\title{
Normtoets, selfdoenopleiding, superkritiek en nog baie meer
}

\author{
W. van Z. de Villiers \\ Departement Stralingstegnologic, Atoomenergickorporasic, Posbus 582, Pretoria, 0001
}

\begin{abstract}
Artikels oor nuwe terme wat in 1996 in hierdic rubrick verskyn het, ${ }^{1.2}$ het heelwat kommentaar uitgelok. Dit het navrae en voorstelle met betrekking tot nuwe terme wat in dic natuurwetenskap en tegnologie gebruik word, ingesluit. Sommige lesers het ook onsekerheid uitgespreck oor die aanbevole Afrikaanse ekwivalente van sommige oucr terme. 'n Aantal van diế navrae word vervolgens vir bespreking aangebied. Lesers word uitgenooi om dit in hul werkskring te bespreek en kommentaar aan die skrywer te stuur.
\end{abstract}

\section{1. benchmark}

Waar dic Engelse term benchmark oorspronklik die eng betekenis gehad het van 'n kwantitatiewe matstaf waarteen vergelykings getref is, hel dit melterlyd in verskeie dissiplines inslag gevind. Saam daarmec hel betekenisverruiming plaasgevind tot op dic vlak waar dit as sinoniem vir standaard, riglyn, norm ol sclis vereiste gebruik word. Een resultaat van dic praktyk is dat daar nog nie cen algemeen aanvaarde Afrikaanse ekwivalent vir dic $1 \mathrm{crm}$ is nic.

Cluver se Rekenaarwoordebock gee die volgende aan:

benchmark : normtoetsing

benchmark problem : normtoctsproblcem

Rekenaargebruikers het ook al ykberekening voorgestcl vir dic geval waar dic spoed of akkuraatheid van ' $n$ bepaalde berckening met 'n gegewe standaard vergelyk word.

A hangend van dic konteks waarin benchmark (as selfstandige naamwoord) gebruik word, word dit dikwels as norm of maatstaf vertaal. Die Terminologievereniging van SuidAfrika stel die volgende voor:

\footnotetext{
benchmark adj. : norm-, riglyn-

benchmark $n$. \{enginecring\} : norm

benchmark $v$. \{enginecring $\}$ : normtoets

benchmark job : bakenpos, normpos

benchmark price : bakenprys, normprys
}

Wannecr ons dus in dic tockoms ons prosesse of praktyke benchmark, moct ons dan maar sê ons normtoets dit, normeer dit of ons voer 'n normtoets uit?

\section{2. hands-on}

Selfdoen-, of dalk selfwerk-, is hiervoor deur'n leser voorgestel. Dit behoort goed te werk in gevalle soos selfdoenondervinding en selfdoenopleiding, en behoort in konteks onderskei tc kan word van gewone prakliese opleiding asook do-it-yourself.

\section{3. abundance}

'n Leser het navraag gedoen oor 'n elegante Alrikaanse term vir solar abundance. Volgens die Nuwe Chemiewoordebock sal dit as volopheid in die son vertaal kan word. Die Fisikawoordebock en Kernbedryfwoordebock bevecl veelleid in die son aan.

Isotope (of isotopic) abundance - dic natuurlike voorkoms van isotope - word deur bogenoemde woordebocke as isotoopverhouding of isotoopveelheid vertaal. (Hockom nic bloot isotoopvoorkoms nic?) Isoloopverthouding word ook algemeen vir abundance ratio gebruik

\section{4. supercritical fluid extraction (SFE)}

Die socke na 'n Afrikaanse term vir hicrdie tegnick wat gebruik word vir die skeiding of isolering van chemiese verbindings uit 'n mengsel of die monster waarin dit voorkom, skep besondere probleme. Dit behels die vertaling van fluid en supercritical, asook dic korrcktc skryfwyse in Afrikaans.

Die selfstandige naamwoord fluid word dikwels in algemene woordebocke soos Bosman, Van der Merwe en Hiemstra se Twectalige Woordebock as vioeistof vertaal. In streng wetenskaplike sin is dit egter nie korrek nie, soos weerspicël word in verskcic vakwoordcbocke wat flü̈ed as Afrikaanse term aangec. 'n Onlangse neiging is om v/oeier te gcbruik, byvoorbecld in die hersiening van die Fisikawoordebock waaraan tans gewerk word.

Dic vertaling van critical gec nog groter probleme. In dic Verklarende Handwoordebock van die Afrikaanse Taal (HAT) word dic byvocglike naamwoord kritiek gebruik vir 'n gevaarlike of crnstige tocstand, asook vir' $n$ kernreaktor waarin 'n beheerde kettingreaksie gehandhaaf word. Wannecr kritick of beoordeling ter sprake is, word krities aanbevecl, asook (verbasend genoeg) in die geval van kritiese temperatuur. De Villiers en andere se Nasionale Woordeboek stem saam met die gebruik van krities in die sin van skerp beoordclend of i.v.m. kritick. Die b.nw. kritiek word deur laasgenocmde aangegee vir "bedenklik" en "beslissend omtrent dic gunstige of ongunstige afloop van 'n sickte, 'n saak of dic lot van 'n mens."

Vakwoordebocke soos dic Nuwe Chemiewoordebock, Fisikawoordcbock, Kernbedryfwoordebock en Terblanche se Tegniese Woordcbock vertaal critical deurgaans as kritiek, bv. kritieke massa, kritieke temperatuur; kritieke hoek, ens. Dit stem ooreen met Louw. se gevolgtrekking dat kritiek altyd in natuurwetenskaplike en tegnologiese sin gebruik word, ongeag of dit na 'n gevaarlike of 'n oorgangstoestand verwys. Daarvolgens sal supercritical dan met stiperkritiek vertial word. (Nogtans is daar heelwat wetenskaplikes wat van kritiese temperatutu praat! Hoe nou gemaak?)

Wat die skryfwyse van supercritical fluid extraction in Afrikaans betref, word dic deurslag gegee deur die s.nw. waarop die b.nw. supercritical betrekking het. Aangesien laasgenoemde die cerste van dic twee selfstandige naamwoorde in dic samestelling omskryf, moet alles vas geskryf word, met dic opsionele gebruik van 'n koppelteken tussen die twee s.nwe. vir beter leesbaarheid. ${ }^{4}$ Dic regte Afrikaanse ekwivalent vir bogenoemde term sal dus superkritiekefluied-ekstraksie ( $S F E$ ) of dalk superkritiekevloeier-ekstraksie wees. 


\section{5. pregnant solution}

Terblanche se Tegniese Woordeboek en verskeic ander bevecl dragtige oplossing aan. Dic Mynbouwoordebock gee pregnamle oplossing.

\section{6. excipient}

Die inerte stof wat by 'n aktiewe geneesmiddel gevoeg word wanneer tablette vervalardig word, is 'n excipient. Dic Aptekerswoordebock en Snyman se Geneeskundige Woordebock gee bindmiddel en bindstof alan. Verskillende uitgawes van Bosman, Van der Merwe en Hiemstra gee bindmiddel, mengmiddel en draer. Sommige larmakoloe verkies weer halpstof of mengmiddel. Lesers wat mel die gebruiksomgewing van die term bekend is, is welkom om hul mening ic gee.

\section{7. speciation}

Op dieselfde manier wat despeciation in dic Nuwe Chemicwoordebock vertaal word, kan die volgende inskrywing vir speciation bygevocg word:

speciation : I. spesiasic

2. spesiëring

\section{8. weatherability}

Hicrdie term word gebruik om die bestandheid van 'n dek- of beskermingslagie teen die weer (buitelug) mee te beskryf. Verweringsbestandheid is as Afrikaanse ck wivalent voorgestel, om dit te onderskei van weerbestandheid vir weather resistance. Daar is hopelik lesers wat meer lig op hierdie saak kan werp.

\section{9. strain(ing) layer}

Dit is 'n lagie wat die spanning absorbeer wat deur byvoorbeeld verskillende termiese-uitsetlingskoëflisiënte in lae aan weers- kante daarvan veroorsaak word. Vervormingsabsorberende laag is tegnies korrek, matar vervormingslaag le makliker op die tong en kan beswalarlik in die betrokke konteks verkeerd verstaan word.

Dic uitgang -ing is waarskynlik oorbolig en mag sells dic betekenis verdraai. Dic weglating daarvan sal dit in pas bring met die volgende voorbeclde uit die Fisikawoordeboek en Kembedryfwoordebock:

strain guage : vervormingsmeter

strain rate : vervormingstempo

\section{Enkele terme uit keramiektegnologie en metallurgie}

Die volgende terme walaroor navrac van lesers ontvang is, bestaan reeds in die Nasionale Termbank by die Nasionale Terminologiediens:

slip : slib ('n lipe kleimassa-suspensic vir die giet van porseIeinware)

engobe : engobe ('n kleilagie wal onder die glasuur op 'n porseleinartikel geplaas word om die basiskleur wit te kry) speiss : speiss ('n As- en/of Sb-bevattende kors in potmetallurgic)

matte : mat ('n metaalsulfiedmengsel as tussenproduk tydens die verwerking van ertse wat sulfiedminerale bevat)

\section{I.ITERATUURVERWYSINGS}

1. De Villiers, W. van Z. (1996). Nuwe terme in chemie en verwante gebiede, S.Afr: Tydskr: Natumrwet. en Tegnol, 15, 35.

2. De Villiers. W. van Z. (1996). Enkele voorbeelde van die wisselwerking lussen samestellers en gebruikers van vakwoordebocke, S.Afi: Tydskr: Nenumrwet. en Tegnol., 15, 78.

3. Louw, D.F. (1987). 'n Kriticse blik op krities/kritick, S.Afi: Tydskr. Natuarnet. en Tegnol., 6, 169.

4. De Villiers, W. van Z. \& Crouse, P.L. (1996). Dic skryfwyse van samestellings met selfstandige naamwoorde, $S . A j t$. Tydskr. Nutuurwet. en Tegnol., 15, 80.

\title{
Afrikaanse vakterme vir Siviele Ingenieurswese
}

\author{
J.E. Smit en A.W. Rohde \\ Departement Sivicle Ingenieurswese, Universiteit van Pretoria, Pretoria, 0002
}

\section{AGTERGROND}

Sivicle ingenicurswese het reeds lank voordat dit as sodanig bekend gestaan het, sy bydrac tot die samelewings van die wêreld gelewer in dic vorm van langalstandwaterleidings, besproeiingswerke, paaie, hawens en bouwerke.

Bewyse van sulke werke wat ecue voor Christus reeds gebou is, is in Egipte, die Midde-Ooste en China gevind. In later tye het Romeinse krygsmanne en ingenieurs beroemd geword vir veral hulle besondere paaic, waterleidings en brûe. Sommige van laasgenoemde werke is vandag nog te sien en in enkele gevalle nog in gebruik.

Die siviele ingenieur wat vandag in Suid-Arrika werksaam is, bevind hom in 'n land waar die werke van sy voorgangers oor die afgelope meer as drichonderd jaar oral met trots staan. Aanvanklik, veral in die vorige ecu, is siviele ingenieurs en landmeters vir SuidAfrika van oorsec bekom, maar namate die bedryf hier te lande gegroei het, is meer en meer siviele ingenicurs aan Suid-A rikaanse universiteite opgelei. Engelsmedium-universiteite hel as eerste opleidingsentra gedien, maar met dic ontstaan van ingenicursfakulteite by dic Universilcile van Stellenbosch, Pretoria en Johanncburg (RAU) het meer Afrikaanssprekende studente die geleentheid gekry om opleiding in hulle moedertal te ontvang. alhoewel teksboeke uitsluitlik in Engels was. Basiese vakke soos Wiskunde, Fisika, Chemie, ens. het reeds oor lyste van vakterme (Eng.-Afr.; Alr.-Eng.) beskik, terwyl daar vir die spesiticke sivicleingenieursvakke vir baic jare daarna nog nie behoorlik gelyste vakterme beskikbaar was nie. Dosente en Alrikaanssprekende 
ingenicurs het dikwels maiar self woorde moes skep, wat met verloop van tyd oor 'n wye spektrum in die praktyk inslag gevind het.

In die studie vir die graad B.Ing.(Siviel) en verwante diplomakursusse moet dic siviele-ingenieurstudent 'n wye verskeidenheid van kennis en begrippe bemeester wat grootliks deur die gesproke en geskrewe woord aan hom oorgedra word. Om die nodige kennis en begrippe so suiwer as moontlik te bemeester, moel dic taal as kommunikasiemedium so suiwer en cenvormig as moontlik wees. Weens snelle ontwikkeling van die verskillende subdissiplines van Siviele Ingenieurswese bestaan die behoefte deurlopend om geskikte Afrikaanse terme te vind, veral vir Engelse ekwivalente wat dikwels nic so duidelik is nie, veral nie vir dic Afrikaanssprekende ingenieur/student nic. Jarelange ervaring met dic opleiding van sivicleingenicurstudente het duidelik getoon dat waar die taal vir die Afrikaanssprekende student 'n probleem is (omdat handbocke in Engels is), hy beslis nic optimaal kan studeer of mocilike begrippe maklik kan baasraak nic.

Dit is ' $n$ alledaagse verskynsel dat dic omgangstaal op vele bouterreine in Suid-Afrika Afrikaans is. In hierdie verband het Jr. Hennie Terblanche se bekende lys Bouterme (voorloper van die bekende Bouwoordeboek), waarvan die eerste Eng.-Afr.-lys in Maart 1951 voltooi is, 'n besondere bydrac tot die Afrikalanse vaktaal gelewer. Sedertdien het die sivicle-ingenicursbedryl' in Suid-Afrika, net soos die boubedryf, met rasse skrede gegroei. Verskeic vakkundiges, waaronder tegnoloë, ingenieurs en taalkundiges het oor ' $n$ bree terrein in beide die openbare en privaat sektor bygedra om geskrifte, veral gebruikshandleidings en ontwerpkodes, ook in Afrikaans op te stel. Dit het die Alrikaanse vaktaal oor die afgelope vier dekades vinnig help uitbou. Insgelyks het ook die vakkennis en spesialisvakgebiede vir siviele ingenieurs gegroci.

Dit is vandag byvoorbecld algemeen om van 'n vervoeringenieur, struktuuringenieur, geotegniese ingenicur, ens. te praat, wat as deskundiges onder die sambreel van Siviele Ingenieurswese werksaam is. Hierdie aspek weerspieël dan weer op sy beurt die hoolvertakkings van vakke wat nodig is vir opleiding in Siviele Ingenieurswese. Bekende voorbeelde hiervan is:

Sivicle Boumateriale;

Geotegniese Ingenicurswese;

Ingenicursgeometric (insluitende Opmeetkunde);

Struktuuringenieurswese;

Vervoeringenicurswese en

Waterboukunde.

Dertig jaar gelede byvoorbeeld het die formele term "Vervoeringenicurswese" nog nie cens in die vakbenamings vir siviele-ingenicurskursusse voorgekom nic. Vandag het Vervocringenieurswese al weer verder ontwikkel met jonger spruite soos byvoorbecld Verkecrsingenicurswese. Saam met elkeen van hierdie nuwe spruite wat uit die hoofstrome ontwikkel het, het nuwe (Engelse) vakterme gekom. Indien die Afrikaanse siviele-ingenicursvaktaal nie wou stagneer of verdwyn nic, moet nuwe Afrikaanse vakterme noodwendig geskep word waar daar nog nie spontaan sulke terme in dic volksmond (ingenieursmond?) ontwikkel het nic.

\section{GEORDENDE LYS VAN VAKTERME}

Gedurende 1995 is daar begin om binne die Departement Siviele Ingenieurswese aan die Universiteit van Pretoria, uit bestaande kernnotas en handbocke vir siviele-ingenicursvakke, lyste van tersaaklike Afrikaanse vakterme op te stel. Dić pogings is georden en afgebaken deur die indeling en inhoud van die voorgeskrewe voorgraladse siviele-ingenieursvakke vir die B.Ing-graad as basis te neem. Daar is ook geskakel met kollegas buite die Departement Siviele Ingenieurswese wat toepaslike dienskursusse soos byvoorbeeld Dinamika, Geologie en Opmeetkunde annbied. Private gesprekke met voltyds praktiserende kollegas buite die Universiteit het ook goeie bydraes tot gevolg gehad.

Die keuse en vertaling van die verskillende vakterme uit Engels na Afrikaans is deurgaans gedoen in samewerking met die verskillende personecllede wat die betrokke vakke dosecr. Mocilike vertalings het dikwels voorgekom en interessante moontlike nuwe woorde het dikwels opgeduik.

In Strukuuringenieurswese byvoorbecld is "hogging moment" en "sagging moment" onderskeidelik vertaal met "kruinmoment" en "dalmoment". Een baie ervare kollega het vir laasgenoemde term doodeenvoudig die term "sakmoment" voorgestel, na aanleiding van byvoorbecld die deurbuiging wat by ' $n$ balk plaasvind.

Toe Geotegniese Ingenieurswese nog in sy kinderskoene was, het die term "heipaal" reeds ingeburger geraak, aangesien die meeste diep fondamentelemente aanvanklik ingeslaan is. Vandag is daar nic net meer "heipale" (letterlik "inslaanpale") nic, maar daar bestaan 'n legio maniere om sulke pale te installeer. 'n "Pile" kan byvoorbecld ingeslaan word of in silu in ' voorafgeboorde gat gegiet word. Om die saak op te helder, is byvoorbeeld die volgende vertalings in die woordelys opgeneem:

$$
\begin{array}{cl}
\text { pile foundations (e.g.: } & \text { paalfondamente (bv.: } \\
\text { augered piles } & \text { boorpale } \\
\text { driven piles) } & \text { heipale) }
\end{array}
$$

Ons praat ook in die algemeen van 'n houtbalk, staalbalk en gewapendebetonbalk. Wat is byvoorbeeld 'n "grondbalk" wat enersyds reeds ingeburger is? Laasgenoemde balk is beslis nic van grond gemaak nic, alhoewel dit waarskynlik wel moontlik is. Omdal die "grondbalk" ("ground beam") op of naby die grondvlak geleë is, gewoonlik vir fonderingdoeleindes, is die bekende "ground heam" in die woordelys vertaal met "fondamentbalk", aangesien die term "grondbalk" misleidend is as dit byvoorbeeld met "houtbalk" of "staalbalk" vergelyk word. Terloops, "ground beam" (Engels) se Amerikaanse ekwivalent is "grade beam".

In Verkeersingenieurswese het meer as een interessante woord opgeduik, byvoorbecld "acceleration" word algemeen met "versnelling" vertaal. Die vervoeringenicurs het egter daarop aangedring dat "deceleration" met "verstadiging" vertaal word en nie "vertraging" nic!

Onder Padingenielırswese is Paddreineringsterme byvoorbecld as ' $n$ afsonderlike groep terme gelys en is die term "hydroplaning" byvoorbeeld met "wielswewing" vertaal. Is hierdie Afrikaanse term nie 'n verbetering op die Engelse term nic'?

'n Ander bekende woord wat dikwels gehoor word, is die bekende "sementpad", maar moet dit nie cintlik 'n "betonpad" wees nic?

In Hidroulika is dic Engelse "irrotational flow" vertaal met die maklik verstaanbare "rotasievrye vloci", of is daar dalk nog 'n makliker, korter vertaling?

Bogenoemde is mar enkele voorbeelde om die soepelheid van dic Alrikaanse vaktaal te illustreer.

\section{SIOTOPMERKINGS}

'n Mens staan nogal verstom as jy begin besef hoe groot die vaktermewoordeskat van ' $n$ voorgraadse siviele-ingenicurstudent moet wees om die nodige vakkennis te kan aanlecr. So 
is daar byvoorbecld minstens 700 vakterme vir Waterboukunde, minstens 400 vakterme vir Geotegniese Ingenieurswese en meer as 900 vakterme vir Struktuuringenieurswese. Vir tweetaligheid (Alr.-Eng.) moet bogenoemde getalle nagenoeg verdubbel word! En onthou bogenoemde getalle is slegs vir drie subdissiplines van die lecrplan vir Siviele Ingenieurswese. Die suksesvolle sivicle-ingenieurstudent se nuwe "aangelecrde vak woordeskat" na skool beloop sonder twyfel dus duisende woorde!

Die poging binne die Departement Siviele Ingenieurswese an die Universiteit van Pretoria om Siviele-ingenieursvakterme te versamel en te orden, het teen die einde van 1996 gevorder tot met die verskyning van 'n formele lys van Sivicleingenicursterme vir voorgraladse studente (Eng.-Alr.). Die lys

\section{'n Nuwe Bouwoordeboek}

Dic oorspronklike Botwwoordeboek, wat deur dic Vaktaalhuro van die Suid-Alrikaanse Akademie vir Wetenskap en Kuns salamgestel en in 1960 deur Tafelberg-uitgewers gepubliseer is, is sedert 1989 hersien en omvallend bygewerk. Die taak om dic vordering en ontwikkeling in dic boutegnologic sedert dic sestigerjare tot en met die negentigerjare met gepaste terminologic en inligting weer te gec, was veel groter as wat destyds besef is, en het lot die helfte van 1995 in beslag geneem.

Dic grootste decl van die navorsingswerk kom uit 'n verskeidenheid bronne - selfs agremènt-sertilikate en literatuur oor innoverende tegnicke en tegnologieë - en is nog deur relatief min vakspesialiste gečvaluecr. Dic belangrikste bydrac sal uitcindelik deur dic oorspronklike Redaksickomitec vir dic Bouwoordeboek gelewer moet word, wanneer dic finale seleksic en keuring van terme plaasvind.

Die NTD is vir 'n deel van dic navorsingswerk deur dic Opleidingsraad vir die Bou-Industric (ORBI) van dic Building Industrics Federation ol South Africa (BIFSA) finansicel ondersteun. Die skenking van R50 000 hel twee jaar van dic navorsingstydperk geborg. Die Departement Boubestuur van dic Universiteit van Pretoria het die fondse geadministreer en kantoorruimte en biblioteck- en rekenaarfasiliteite aan dic navorsingsassistent beskikbaar gestel. In hierdic tydperk kon waardevolle insette van die vakspesialiste van die Universiteit bygewerk word. Sedert 1992 tot middel 1995 is dic navorsing deur die NTD gefinansier, en verdere werk word deur terminoloë gedoen. ' $n$ Bydrac in die vorm van kommentaar deur vakspesialiste is nou dringend nodig om die terminologie te evalueer en dic juistheid daarvan te bepaal.

'n Belangrike deel van die werk wat sedert navorsing afgehandel is, is HOP-gerig. Volgens prioriteit en op aanvraag uit die boubedryf is 'n aantal tegniese termlyste per vakgebied uit die nagevorste datakorpus onttrek. Dit is met relevante terminologic uit die onderskeic vaardigheidsregisters vir ellike ambagte van dic Opleidingsraad vir die Bou-Industric aangevul. Met die uitsondering van Tekenkantoorterme, wat afkortings en simbole bevat en slegs tweetalig (Eng./Afr.) aangebied word, is hierdie lyste van ekwivalente in twee bykomende amptelike landstale voorsicn. Aanvanklik het ORBI versock dat ekwivalente in Zulu en Tswana bygevoeg word. Dic versock is later gewysig, en tans word Engels/ Afrikaans/Zulu/Sepedi verskaf. Die uitcindelike ideal is om mettertyd ' verteenwoordigende terminologie vir dic Boubedryf in al die amptelike landstale tot stand te bring. is gerekenarisecr en terme vir elke subdissipline is afsonderlik en gebruiksvriendelik ge-organiseer. Bydraes en voorstelle ter verbelering en uitbouing hicrvan is beslis baic welkom en moet aan dic adres van dic Departement Siviele Ingenieurswese, Universiteil van Pretoria, gerig word.

Die hoop word gekoester dat die genoemde lys van vakıerme tot voordeel van die student, dosent en rolspelers in dic praktyk sal strek en dat die Alrikaanse valktaalbevordering daarby batat sal vind. Hierdie lys van vakterme is ' $n$ verdere byvoeging $10 t$ dic talle bestaande Afrikaanse vaktaalwoordeboeke en woordelyste. Die Alrikaanse vaktail is inderdaad nog springlewendig!
Gereedskap, steierterminologic, tekeninge en materiale oorvleuel soms in die onderskeic registers. Dit beteken egter nie dat terme oor en oor behandel moel word nic, omdat dupliserings uitgeskakel word wanneer dic lyste vir die verskillende ambagle tot 'n eksperimentele vakwoordebock vir die ambagte en ander subvakgebiede gekonsolideer word.

Omdat daar onsekerheid oor die juistheid van sommige tcrme beslaan, is die lyste slegs oppervlakkig geredigeer. Dit is in oorleg met lede van die Redaksickomitec gedoen, om te voorkom dat tydrowende afrondingswerk gedoen word aan terme wat moontlik later deur vakspesialiste geskrap word. Dic termlyste wat uitgestuur word, moel dus as konseplyste beskou word wat eers gefinaliseer kan word nadat kommentaar uit die boubedryl ontvang en bygewerk is.

Om hierdie rede word belanghebbendes versock om spesialiste uit hul organisasies te benoem wat oor 'n tydperk kommentaar kan lewer oor 'n spesifieke vakgebied of vakgebiede. Die N'TD verwag nie van bydraers groot navorsingsinsette nie; slegs om fouticwe inligting onder dic NTD se aandag te bring en lecmtes te vul wat, volgens hul kennis en ervaring in die vak, onder dic aandag kom.

Dic cerste briewe word ecrsdaags na die cerste medewerkers versend wat hulp aangebied het. Sodra die name en posadresse van bykomende medewerkers ontvang word, sal verdere lyste versend word. Daar sal 'n keerdatum per lys gestel word, wat medewerkers asseblief moet probeer nakom, aangesien dic behoefte aan 'n nuwe Bouwoordeboek lank reeds dringend is.

Lyste wat gereed is om versend te word, is

* Tweetalige 'Tekenkantoorterme (Eng./Air.;Afr./Eng.) met gestandaardisecrde alkortings en simbole

* Gereedskaplys (Eng./Air./Zulu/Tswana)

* Viertalige Pleister- en Teëlterminologie (Eng./Alr./Zulu/ Tswana)

* Viertalige Steenmesselterminologic (Eng./Afr./Zulu/Tswana)

* Viertalige Verfterminologie (Eng./Afr./Zulu/Sepedi)

Daar word tans gewerk aan die invoeging van Zulu- en Sepediekwivalente vir viertalige termlyste vir Skrynwerk en meubelmakery, Terrein en terreinbestuur. Ambagte en Arbeidsregulasies, Boureg, en Bourekenc.

Hocwel alle belanghebbendes moontlik nog nie dic Alrikataalckwivalente van dic terme nodig het nic, word dic 
kennis en ervaring van spesialiste in die vakgebiede steeds benodig om dic Engels-Afrikaanse lyste te evalueer.

Afgesien van die genoemde sublyste, sal die gekoördineerde data, wat die hele boubedryl verteenwoordig, so gou moontlik per alfabetletter vir kommentaar uitgestuur word aan vakkenners wat ingewillig hel om met hierdie enorme talak te help. Die tïnale keuring vir publikasiedocleindes sal aan die Voorsitter en lede van dic oorspronklike redaksickomilee van die woordebock oorgelaat word.

Individue en/of instansies wat op enige wyse 'n bydrae gelewer het, sal in die voorlopige lessenaarpublikasies en in die beoogde Nuwe Bonwoordeboek volledige erkenning vir hul bydracs ont vang.

\section{Skrywes in hierdie verband kan gerig word aan:}

\section{Susan Rocts}

Ingenicurswese en Tegnologice, NTD, Departement van Kuns, Kultuur, Wetenskap en Tegnologie,

Prival sak $\times 894$, Pretoria, 0001

Faksnr:: (012) 3254943

E-pos: VT12@acts2.pwv.gov.za 